\title{
High Levels of Insensitivity to Phosphonate Fungicides in Pseudoperonospora humuli
}

\author{
David H. Gent, ${ }^{1,2, \dagger}$ Mary Block, $^{3}$ and Briana J. Claassen ${ }^{2}$ \\ ${ }^{1}$ Forage Seed and Cereal Research Unit, U.S. Department of Agriculture Agricultural Research Service, Corvallis, OR 97331 \\ ${ }^{2}$ Department of Botany and Plant Pathology, Oregon State University, Corvallis, OR 97331 \\ ${ }^{3}$ Department of Crop and Soil Science, Oregon State University, Corvallis, OR 97331
}

\begin{abstract}
Phosphonate (phosphite; $\mathrm{HPO}_{3}^{-2}$ ) is fungicidal against oomycetes and certain other organisms. The Fungicide Resistance Action Committee has deemed phosphonate to be at low risk of resistance development, and reduced sensitivity to phosphonate has been reported only occasionally in plant pathogens. Reduced sensitivity to the fungicide fosetyl-Al was documented in the hop downy mildew pathogen, Pseudoperonospora humuli, in the early 2000 s, but disease caused by insensitive isolates could still be managed commercially if the fungicide rate was doubled from 2.24 to $4.48 \mathrm{~kg} / \mathrm{ha}$. In this research, we document the occurrence of isolates of $P$. humuli in Oregon that possess even higher levels of insensitivity to fosetyl-Al and other phosphonate fungicides. The median estimated effective concentration required to reduce infection by $50 \%\left(\mathrm{EC}_{50}\right)$ for isolates collected from two farms reporting disease control failures was $2.7 \%$ (vol/vol) phosphonate (range $=1.6$ to 164.2), which was 1.6 times (range $=0.9$ to 96.0) the maximum labeled rate of the phosphonate fungicide utilized. In contrast, the median $\mathrm{EC}_{50}$ for isolates obtained from experimental plots that have received only a single application of a phosphonate fungicide was $0.6 \%$ ( $\mathrm{vol} / \mathrm{vol}) \mathrm{phos}-$

a plant nutrient product containing an unspecified level of phosphorous acid were linearly related. Insensitivity to the maximum allowable rate of a phosphorous acid fungicide was widespread within and among hop farms in Oregon. Among 54 isolates assayed for phosphonate insensitivity, $96 \%$ had $\mathrm{EC}_{50}$ values that exceeded the maximum allow rate of the fungicide used in the assays. Field studies conducted in 2 years further demonstrated that a phosphorous fungicide, a nutrient product containing phosphorous acid, and fosetyl-Al failed to provide commercially acceptable suppression of downy mildew when applied at the maximum allowable rates and even double these rates, whereas fungicides with different modes of action provided $91 \%$ or greater disease control. The whole of this research indicates that $P$. humuli has been selected to tolerate fosetyl-Al and other phosphonate fungicides at rates four times greater than those used earlier to obtain satisfactory suppression of downy mildew. This finding has implications for management of the disease not only in Oregon but also, in other production regions should insensitive isolates be introduced on infected planting material.
\end{abstract} phonate (range $=0.11$ to 2.3 ) or 0.3 times the maximum allowable rate. Sensitivity of isolates to a phosphorous acid fungicide, fosetyl-Al, and
Keywords: chemical, disease management, field crops, oomycetes, other
Phosphonate (phosphite; $\mathrm{HPO}_{3}^{-2}$ ) is the anionic fungicidal compound in certain fungicide products and the fungicidal metabolite of fosetyl salts, such as aluminum tris- $O$-ethyl phosphonate (fosetyl-Al) (Ouimette and Coffey 1989a, b), being classified by the Fungicide Resistance Action Committee as group P07 (formerly 33). Phosphonate possesses fungicidal activity primarily against diseases caused by oomycetes (Cohen and Coffey 1986) and to a lesser extent, certain diseases caused by true fungi (Dufour and Corio-Costet 2013) and bacteria (McGuire 1988; Montesinos and Vilardell 2001). Other products possessing salts of phosphorous acid $\left(\mathrm{H}_{3} \mathrm{PO}_{3}\right)$ are marketed as plant fertilizer supplements (Brown et al. 2004), although the phosphorous acid component of such products is stable in plants (Ouimette and Coffey 1989a, b), lacks direct nutritive value (Förster et al. 1998), and must be converted to phosphate by microbial activity to be plant available (Adams and Conrad 1953; McDonald et al. 2001). The phosphorous acid content of these products varies but often is substantially less (e.g., 20\% or less of the formulated product) compared with phosphonate products registered as fungicides (approximately $50 \%$ of the formulated

${ }^{\dagger}$ Corresponding author: D. H. Gent; Dave.Gent@usda.gov

Funding: Financial support was provided by Agricultural Research Service grant CRIS 2072-21000-046-00.

The author(s) declare no conflict of interest.

Accepted for publication 18 December 2019.

This article is in the public domain and not copyrightable. It may be freely reprinted with customary crediting of the source. The American Phytopathological Society, 2020. product). However, these products still contain sufficient phosphorous acid to suppress disease (Brown et al. 2004; Förster et al. 1998).

The physical mode of action of phosphonate is unique among fungicides in that the molecule is systemic in plants, moving both basipetally and acropetally, permitting foliar applications or trunk injections to suppress disease on both aerial and below-ground tissues (Coffey 1987; Cohen and Coffey 1986; Johnson et al. 2004; Ouimette and Coffey 1990). Phosphonate is long lived in plants (Malusà and Tosi 2005), with residue levels varying based on application method, timing, and certain tissue sinks (McLeod et al. 2018). Residues are detectable in multiple plant tissues weeks to months after foliar and soil application (Ouimette and Coffey 1989a, b), decreasing with time on a logarithmic scale (Long et al. 1989). The mode of action of phosphonate involves direct fungicidal activity on mycelial growth and spore formation in oomycetes, with the level of activity proportional to concentration of phosphonate ion in the tissue (Cohen and Coffey 1986; Dolan and Coffey 1988; Fenn and Coffey 1989; Stehmann and Grant 2000). Potential indirect effects of phosphonate on disease owing to stimulation of host defense responses are also reported (Dunstan et al. 1990; Guest and Bompeix 1990; Guest and Grant 1991; Smillie et al. 1989).

The Fungicide Resistance Action Committee has deemed phosphonate to be at low risk of resistance development (https://www.frac.info/). Reduced sensitivity to phosphonate has been reported only occasionally in oomycetes, both from spontaneous mutants generated in vitro (Bower and Coffey 1985; Dolan and Coffey 1988; Sanders et al. 1990) and in natural populations (Adaskaveg et al. 2017; Brown et al. 2004; Cohen and Samoucha 1984; Nelson et al. 2004). The direct fungicidal activity of phosphonate seems to be central to development of resistance in oomycetes as evidenced by the ability to select resistant mutants in culture, the correspondence of in vitro and in vivo activity, and metabolic changes detectable in the pathogen in the absence of a host (Dolan and Coffey 1988; Fenn and Coffey 1989; Niere et al. 1994). 
In the specific instance of downy mildew of hop (caused by Pseudoperonospora humuli), fosetyl-Al has been an important fungicide for management of the disease in the western United States since the early 1980s (Nelson et al. 2004), particularly after insensitivity to phenylamide fungicides developed (Klein 1994; Nelson et al. 2004). Fosetyl-Al displays some level of postinfection activity against downy mildew for 3 days in leaves but as long as 8 days in shoots (Gent et al. 2015b). As early as 1982, Hunger and Horner (1982) demonstrated the efficacy of a single application of fosetyl$\mathrm{Al}$ (which they called by the synonymous name efosite-Al) against hop downy mildew and advocated annual rotation of systemic fungicides to avoid selection of insensitive strains. However, this strategy was not widely adopted or possible after the rapid development and persistence of insensitivity to phenylamide compounds in $P$. humuli (Gent et al. 2008; Klein 1994). Thus, fosetyl-Al and less expensive related phosphonate fungicides have been used extensively for management of downy mildew for three decades (Nelson et al. 2004). The product label for Aliette 80WDG (Bayer Crop Science, Research Triangle Park, NC) indicates that up to four applications may be made per year to hop. Other phosphonate products, such as FUNGIPHITE (45.5\% mono- and dipotassium salts of phosphorous acid; Plant Protectants LLC, Visalia, CA) permit six applications per year. In our experience, some hop growers may apply various phosphonate products, including products marketed as plant fertility supplements, more than six times per year.

Nelson et al. (2004) compared the sensitivity of populations of $P$. humuli obtained from Oregon and northern Idaho, where downy mildew occurs annually (Gent et al. 2010), with populations from semiarid hop production regions in southern Idaho and Washington state, where downy mildew occurs less frequently and less severely (Johnson et al. 1983; Skotland and Johnson 1983). The fosetyl-Al estimated effective concentration required to reduce infection by $50 \%\left(\mathrm{EC}_{50}\right)$ was approximately threefold greater in Oregon and northern Idaho versus Washington. Consequently, a Special Local Need registration was sought that permitted a doubling of the allowable rate of fosetyl-Al to $4.48 \mathrm{~kg} / \mathrm{ha}$ of fosetyl-Al (as Aliette 80WD; Bayer Crop Science) to manage insensitive strains of the pathogen (Gent et al. 2015a).

During two field trials in Oregon in 2016, we documented little to no control of downy mildew in plots that received regular applications of the highest allowable rate of a commonly used phosphonate fungicide (Gent 2017a, b). This motivated the studies reported herein, which sought to determine if resistance to even higher rates of phosphonate has developed in the pathogen population. The specific objectives of this research were to (i) determine if downy mildew control failures are associated with reduced sensitivity to various formulations of phosphonate, (ii) quantify the degree of disease control from phosphonate where insensitive isolates are present, and (iii) determine the frequency of reduced sensitivity in hop yards in Oregon.

\section{Materials and Methods}

Plant materials. Plants of the downy mildew-susceptible cultivar Pacific Gem were propagated from softwood cuttings and maintained in a greenhouse free of downy mildew. The greenhouse was maintained at 20 to $25^{\circ} \mathrm{C}$ with a 14-h photoperiod. Plants were grown in 7.6-cm-diameter pots in Sunshine Mix \#1 (SunGro Horticulture, Hubbard, OR) for 14 to 21 days before use in an experiment. Sunshine Technigro 20-20-20 Plus fertilizer with micronutrients (Sun Gro Horticulture) was applied with each irrigation to promote leaves maximally susceptible to downy mildew.

Isolates and maintenance. In 2016 and 2017, diseased shoots with symptoms and signs of systemic infection were collected from eight commercial hop yards in western Oregon and from an experimental hop yard near Corvallis, Oregon. In each commercial yard or the experimental yard, a single diseased shoot was collected from each of 10 to 35 plants.

Diseased shoots were brought to a laboratory, the stems were placed in beakers of water, and the shoots were misted and bagged overnight to induce sporulation. The following day, sporangia were washed from the abaxial leaf surface with sterile water applied from an airbrush sprayer, adjusted to a concentration of approximately 10,000 sporangia per $1 \mathrm{ml}$, and reinoculated onto one or several potted plants of cultivar Pacific Gem. Inoculated plants were incubated in a plastic barrel container (SNAPWARE, Mira Loma, CA) as described by Mitchell et al. (2011). Inoculum from each diseased shoot was maintained as a distinct, although heterogeneous, inoculum source because fungicide sensitivity of a single sporangium isolate derived from a diseased shoot is well correlated with that of heterogeneous inoculum derived from the same shoot (Gent et al. 2008). Each shoot "isolate" was maintained separately on whole plants using the methods of Mitchell et al. (2011).

Fungicide sensitivity assays. Estimated $E_{50}$ of $\mathrm{P}$. humuli isolates. Fungicide sensitivity assays were conducted using a modification of the methods reported by Gent et al. (2008), Klein (1994), and Nelson et al. (2004) to determine the sensitivity of isolates of $P$. humuli to various phosphonate compounds. Plants of cultivar Pacific Gem were treated with a series of concentrations of the formulated fungicide FUNGI-PHITE. There are many phosphonate fungicides and other products containing phosphorous acid that one could use for such studies, and we selected this product simply because FUNGI-PHITE is registered as a fungicide by the U.S. Environmental Protection Agency and used commercially in the hop industry. To determine the $\mathrm{EC}_{50}$, the leaves of potted hop plants were treated at concentrations of $0,0.43,0.86,1.28,1.71,3.41,6.83$, and $9.78 \%$ (vol/vol) phosphorous acid using a handheld atomizer (Nalgene, Rochester, NY) to deliver a fine spray to the abaxial surface of the leaves to just before the point of runoff. These concentrations were selected based on the FUNGI-PHITE label for hop, which permits a maximum rate of $1.71 \%$ phosphorous acid (i.e., 3.5 liters of FUNGI-PHITE in an application volume of 93.5 liters/ha for foliar applications; $45.5 \%$ active ingredient). Therefore, the dilution series consisted of the equivalent of $0,1 / 4,1 / 2,3 / 4,1,2,4$, and $6 \times$ the maximum allowable rate. Isolates collected from commercial fields where insensitivity to phosphonate was suspected were not assayed with the $1.28 \%$ rate, whereas isolates collected from experimental plots where insensitivity was not suspected were not assayed with the $9.78 \%$ rate.

Twenty-four hours after treatment, leaves three to five nodes from the growing point were removed, and leaf disks $1 \mathrm{~cm}$ in diameter were removed from the leaves and placed abaxial surface upward onto petri dishes containing $1 \%$ water agar. On each of seven disks per fungicide concentration, three spots were inoculated with a $10-\mu l$ droplet containing approximately 100 sporangia. Thus, there were 21 inoculation sites per isolate $\times$ fungicide concentration. The inoculated disks were incubated at $20^{\circ} \mathrm{C}$ with a 14 -h photoperiod provided by fluorescent lights overnight before the water droplet and any remaining inoculum were removed by aspiration. The leaf disks were incubated for an additional 6 to 10 days, and then, they were examined with the aid of a stereomicroscope to determine the incidence of inoculation sites with sporulating colonies of $P$. humuli.

The reproducibility of the assay was established by assaying a subset of 14 isolates twice. The accuracy, precision, and correspondence correlation of the $\mathrm{EC}_{50}$ values obtained from the two replications of the assay were quantified by the bias correction factor $\left(C_{\mathrm{b}}\right)$, Pearson's correlation coefficient $r$, and the concordance correlation coefficient $\left(\rho_{\mathrm{c}}\right)$ (Madden et al. 2007).

In total, 25 isolates from commercial yards were assayed to determine the $\mathrm{EC}_{50}$ for phosphorous acid, with these isolates being derived from five yards on two hop farms where downy mildew control failures with phosphonate fungicide were noted by the growers. The phosphorous acid sensitivity of the exposed population was compared with that of 32 isolates derived from experimental plots (cultivars Willamette and Symphony) near Corvallis, Oregon, where there was limited use (one application in 2009) of a phosphonate fungicide over the previous 13 years since the yard was established (Woods et al. 2014).

Relative $\mathrm{EC}_{50}$ values as defined by Noel et al. (2018) and Sebaugh (2011) were estimated using probit regression in the PROBIT procedure in SAS version 9.4 (SAS Institute, Cary, NC). The proportion of 
inoculation sites with sporulation was regressed on the common logarithm of fungicide dose to estimate $\mu$, the dosage with $50 \%$ probability of a response. Natural response rates based on controls treated with only water were estimated using the "optc" option in the PROBIT procedure to adjust the $\mathrm{EC}_{50}$ values for natural mortality. This analysis assumed that the dose-response was symmetric and that the lower asymptote was potentially greater than zero, but hermetic effects were not considered (Noel et al. 2018). Histograms based on the estimated $\mathrm{EC}_{50}$ values for phosphorous acid were constructed for both populations. The distribution of estimated $\mathrm{EC}_{50}$ values was tested for equivalency by the Kolmogorov-Smirnov (K-S) test using the NPAR1WAY procedure in SAS. Exact $P$ values were calculated by Monte Carlo estimation using the default settings in the NPAR1WAY procedure.

A subset of 11 isolates with varying levels of sensitivity to phosphonate was similarly assayed with fosetyl-Al and a fertilizer product reported to contain an unspecified amount of phosphorous acid but $40 \%$ available phosphate derived from phosphorous acid, ammonium hydroxide, and potassium hydroxide (Nutri-Phite Magnum; Verdesian Life Sciences, Cary, NC). Assays with fosetyl-Al were conducted similarly by treating plants with Aliette 80WDG at 0 , $1.5,3,6,11.97,23.97$, or $35.93 \%$ (wt/vol) fosetyl-Al. These rates are equivalent to $0,1 / 8,1 / 4,1 / 2,3 / 4,1,2,4$, and $6 \times$, respectively, the maximum rate allowable on the Special Local Needs label for hop grown in Oregon (i.e., $5.6 \mathrm{~kg} / \mathrm{ha}$ of Aliette 80WDG in an application volume of 93.5 liters). The maximum recommended rate of Nutri-Phite Magnum is $2 \%$ ( $\mathrm{vol} / \mathrm{vol}$ ) for foliar applications. Therefore, rates used in the dilution series were $0,0.25,0.5,1,1.5,2,4$, 8 , and $12 \%$, corresponding to $1 / 8$ to $6 \times$ the maximum recommended rate but an unknown amount of phosphorous acid owing to the ambiguity in the label. The resulting $\mathrm{EC}_{50}$ values were compared among the three products by linear regression. Analyses were conducted using the REG procedure in SAS version 9.4. With a sample size of 11, statistical power to detect a correlation (effect size) $=0.6$ was 0.67 assuming $\alpha=0.05$ and a one-sided test (i.e., a positive correlation) according to the power tables reported in Cohen (1988). Power was 0.83 if the correlation was 0.7 .

Prevalence of phosphonate insensitivity in Oregon hops. Downy mildew isolates were obtained from 54 diseased shoots collected from a total of six commercial hop farms in Oregon in 2017 to determine the incidence of insensitivity to phosphonate. In this study, a discriminatory dose was utilized because we were concerned only with the incidence of insensitivity to the maximum allowable rate and not the level of insensitivity. Assays were conducted as described previously, except that only a single dose of phosphorous acid $(1.71 \%$ [ $\mathrm{vol} / \mathrm{vol}]$; equivalent to the $1 \times$ rate of FUNGI-PHITE) and a water control were applied. An isolate was considered insensitive if sporulation developed on at least $50 \%$ of the inoculation sites (i.e., the absolute $\mathrm{EC}_{50}$ was greater than the $1 \times$ rate).

Fungicide efficacy studies. Three field studies were conducted during 2017, 2018, and 2019 to quantify control of downy mildew in locations where reduced sensitivity to phosphonate fungicides was present. In all years, studies were conducted in three separate commercial yards of cultivar Nugget (Haunold et al. 1984) on a farm near Hubbard, Oregon, where high levels of insensitivity to phosphonate were confirmed based on $\mathrm{EC}_{50}$ assays (described above and below). In 2017, four fungicide treatments were evaluated consisting of phosphorous acid (4.68 liters/ha of FUNGI-PHITE), fosetyl-Al $(5.6 \mathrm{~kg} / \mathrm{ha}$ of Aliette $80 \mathrm{WDG})$, a premix of oxathiapiprolin + mandipropamid ( 0.4 liters/ha of Orondis Ultra formulated as $2.77 \%$ oxathiapiprolin $+23.1 \%$ mandipropamid; Syngenta Crop Protection, Greensboro, NC), and fluopicolide (0.29 liters/ha of Presidio Fungicide formulated as $39.5 \%$ fluopicolide; Valent U.S.A., Walnut Creek, CA). The oxathiapiprolin + mandipropamid and fluopicolide treatments were amended with $0.25 \%$ (vol/vol) R-11 surfactant (Wilbur-Ellis, San Francisco, CA). These fungicide treatments were compared with nontreated plots that served as a check. A plot consisted of seven plants in a single row, with plants separated by $2.3 \mathrm{~m}$ within a row and $4.6 \mathrm{~m}$ between rows. Plots were arranged in a randomized complete block design with five replications.
Fungicides were directed to both sides of plants using $\mathrm{CO}_{2}$-pressurized backpack sprayer and a $61-\mathrm{cm}$ boom equipped with two $8002 \mathrm{~V} 5 \mathrm{noz}-$ zles. Applications were made in a volume equivalent to 327 liters/ha at a pressure of approximately $207 \mathrm{kPa}$. Fungicides were applied three times at 14-day intervals, with applications on 17 April, 2 May, and 15 May.

In 2018 and 2019, the treatments and experimental design were similar to 2017 experiment but with the exception that three additional treatments were evaluated. These treatments were FUNGIPHITE and Aliette 80WDG at twice the maximum rates allowed on the manufacturers' labels (i.e., 9.36 liters/ha of FUNGI-PHITE and 11.2 liters/ha of Aliette 80WDG) and the fertilizer product Nutri-Phite Magnum applied at the maximum rate recommended for hop (4.68 liters/ha). Applications were made on three dates in 2018: 18 April, 2 May, and 9 May. In 2019, applications were made on five dates: 10 April, 24 April, 8 May, 23 May, and 3 June. Additional applications were made in 2019 to extend the duration of the study owing to relatively low disease pressure in early spring. To ensure disease development, in 2019 the plots were irrigated by overhead sprinklers once a week for approximately $4 \mathrm{~h}$ during the late afternoon beginning 17 May.

Levels of downy mildew were assessed by counting the number of shoots with signs and symptoms of systemic downy mildew on each plant. Disease evaluations were conducted just before the first application was made to quantify uniformity of preexisting disease and then, every 2 weeks for 8 (2017 and 2018 studies) or 10 weeks (2019 study). Area under the disease progress curve (AUDPC) was calculated by plant (subsamples within each replicate block) using the trapezoidal integration method (Madden et al. 2007) and analyzed in a general linear mixed model with random factors for block and block $\times$ treatment. AUDPC was log transformed to stabilize variances before analysis. Statistical models were fit in SAS version 9.4 using the GLIMMIX procedure.

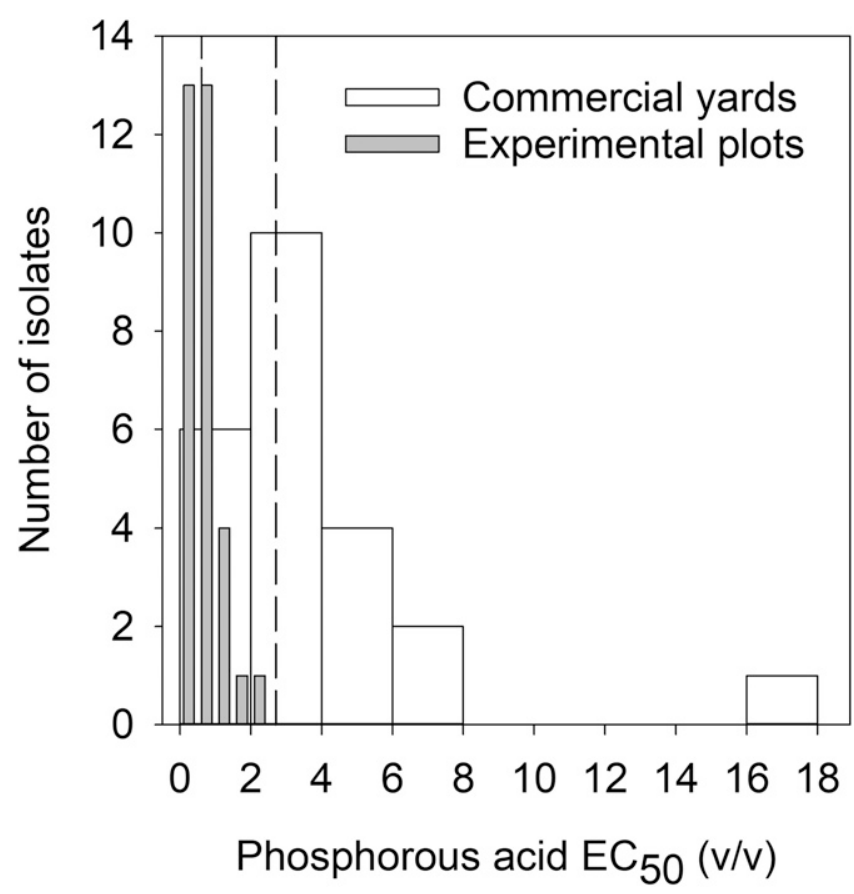

Fig. 1. Distribution of phosphorous acid estimated effective concentration required to reduce infection by $50 \%\left(\mathrm{EC}_{50}\right)$ values among 25 isolates of Pseudoperonospora humuli collected from two commercial hop farms in Oregon where phosphonate fungicides failed to control downy mildew. Overlaid are similar data for 32 isolates collected from experimental plots that received only one application of a phosphonate fungicide since 2005. Dashed lines indicate the median of the distributions. The distribution of $\mathrm{EC}_{50}$ values was statistically different based on the Kolmogorov-Smirnov test $(P<0.0001$ based on 10,000 Monte Carlo simulations). Table 2 details the efficacy of downy mildew control with phosphonate and other fungicides in commercial yards where some of these isolates were obtained. 
Estimation of power with a mixed effect model is complicated when comparing multiple treatments because one has to make multiple assumptions about treatment means and variances; additionally, explicit formulas for calculating power do not exist (Gent et al. 2018). We used an exemplar data approach (Gent et al. 2018) and examined plausible scenarios to determine the minimum detectable effect size given the experimental design. We assumed AUDPC of 1,000 for the nontreated plots; five replications; log transformation of the data to stabilize variances; a one-sided test with $\alpha=0.05$; and estimated variance components for block, block $\times$ treatment, and residual terms of $0.01,0.03$, and 0.08 . With these assumptions, power to detect a treatment effect was 0.69 when mean disease in at least one treatment was reduced $40 \%$ and 0.92 when disease was reduced $50 \%$ compared with the nontreated control. Power was $>0.99$ when disease levels in at least one treatment were reduced $90 \%$.

\section{Results}

Fungicide sensitivity assays. Estimated $E C_{50}$ of $\mathrm{P}$. humuli isolates. Based on results of 14 isolates assayed twice independently, $C_{\mathrm{b}}=0.81, r=0.49$, and $\rho_{\mathrm{c}}=0.39$. As expected, both measures of precision and bias were less than one. Thus, variability in the assay was because of both imperfect precision $(r=0.49)$ and slight bias $\left(C_{\mathrm{b}}=\right.$ 0.81 ) between runs.

The median $\mathrm{EC}_{50}$ for isolates collected from the two farms reporting control failures was $2.7 \%(\mathrm{vol} / \mathrm{vol})$ phosphonate (range $=1.6$ to 164.2), which is 1.6 times (range $=0.9$ to 96.0 ) the maximum labeled rate of the phosphonate fungicide utilized (Fig. 1). The distribution of $\mathrm{EC}_{50}$ values was right skewed, with extremely high levels of insensitivity in some isolates. In contrast, the median $\mathrm{EC}_{50}$ for isolates obtained from experimental plots that received only a single application of a product containing phosphorous acid was $0.6 \%$ ( $\mathrm{vol} / \mathrm{vol})$ phosphonate (range $=0.11$ to 2.3 ) or 0.3 times the maximum allowable rate (Fig. 1). The distribution of $\mathrm{EC}_{50}$ differed between the commercial fields and the experimental plots as determined by significance of the K-S test (K-S statistic $=0.938 ; P<0.0001)$.

There was a significant linear relationships between the sensitivity of isolates to the phosphorous acid fungicide FUNGI-PHITE, fosetyl-Al, and the nutrient product Nutri-Phite Magnum (Fig. 2) Coefficients of determination varied from $R^{2}=0.44$ for fosetyl-Al and Nutri-Phite Magnum to $R^{2}=0.67$ for the phosphorous acid fungicide FUNGI-PHITE and Nutri-Phite Magnum. The slopes of regressions were positive, and the $95 \%$ confidence intervals for the slope parameter estimates did not include zero in any instance $(P \leq 0.023)$, confirming cross-resistance between these compounds. Sensitivity of $P$. humuli to each compound was linearly related, although the slope of regression lines were less than one in two instances. The
95\% confidence intervals for the slope of the regressions were 1.23 to 5.43 for FUNGI-PHITE versus fosetyl-Al (Fig. 2A), 0.29 to 3.48 for Nutri-Phite Magnum versus fosetyl-Al (Fig. 2B), and 0.25 to 0.82 for NutriPhite-Magnum versus FUNGI-PHITE (Fig. 2C).

Prevalence of phosphonate insensitivity in Oregon hops. Insensitivity to the $1 \times$ rate of FUNGI-PHITE was widespread within and among hop farms. Among the 54 isolates assayed for phosphonate insensitivity, $75 \%$ of the inoculation sites produced sporulating colonies. Based on the proportion of inoculation sites that sporulated, the absolute $\mathrm{EC}_{50}$ exceeded the $1 \times$ rate of FUNGI-PHITE for $96 \%$ of the isolates (Table 1). Among the six farms from which isolates were collected, every isolate assayed was deemed insensitive to the $1 \times$ rate on all farms except Farm \#3.

Fungicide efficacy studies. In all experiments, downy mildew was present at similar levels in plots on the date of the first application independent of the treatment. In 2017, plants treated with FUNGI-PHITE or fosetyl-Al had similar levels of downy mildew as nontreated plants based on AUDPC (Table 2). In contrast, the severity of downy mildew was reduced at least 11 -fold $(91.3 \%$ disease control) in plots treated with oxathiapiprolin + mandipropamid or fluopicolide. Disease levels were similar on plants treated with either of these fungicides (Table 2).

Table 1. Frequency of insensitivity to a phosphonate fungicide detected in isolates of Pseudoperonospora humuli from six hop farms in western Oregon in 2017

\begin{tabular}{|c|c|c|c|}
\hline Farm & Isolates & $\begin{array}{l}\text { Inoculation sites } \\
\text { sporulating }(\%)^{\mathrm{y}}\end{array}$ & Insensitive isolates $(\%)^{\mathrm{z}}$ \\
\hline 1 & 9 & 84 & $9(100)$ \\
\hline 2 & 9 & 77 & $9(100)$ \\
\hline 3 & 9 & 68 & $7(77.7)$ \\
\hline 4 & 10 & 84 & $10(100)$ \\
\hline 5 & 10 & 68 & $10(100)$ \\
\hline 6 & 7 & 68 & $7(100)$ \\
\hline Total & 54 & 75 & 96 \\
\hline
\end{tabular}

${ }^{y}$ Leaf disks were removed and placed on water agar $24 \mathrm{~h}$ after hop plants were treated with a phosphonate fungicide (FUNGI-PHITE; Plant Protectants LLC, Visalia, CA) at a concentration equivalent to the maximum allowable rate for hop ( $1.71 \%$ [vol/vol] phosphorous acid). For each isolate, seven leaf disks were inoculated in each of 3 sites (21 inoculation sites in total) with approximately 100 sporangia of $P$. humuli. Values reported are the mean percentages of inoculation sites with sporulation of $P$. humuli 7 to 10 days after inoculation.

${ }^{\mathrm{z}}$ An isolate was considered insensitive if the pathogen sporulated on $>50 \%$ of the inoculated sites (i.e., the estimated effective concentration required to reduce infection by $50 \%$ exceeded the maximum allowable rate).
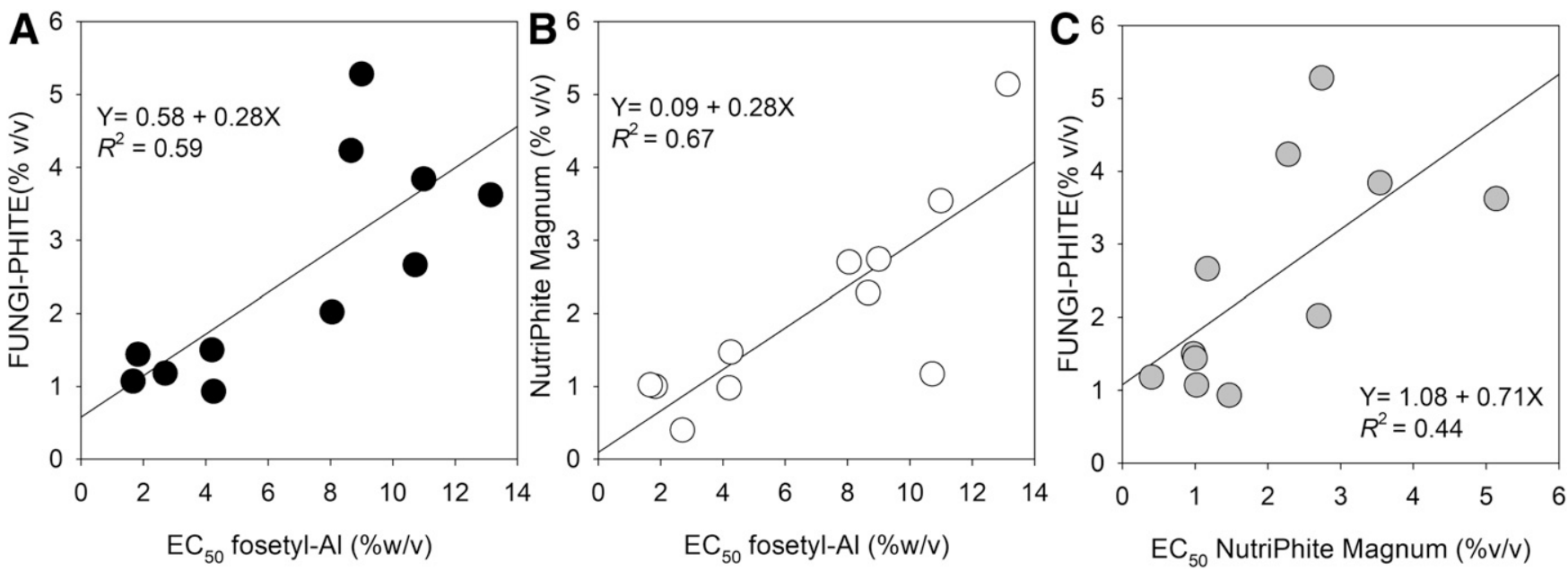

Fig. 2. Relationship between estimated effective concentration required to reduce infection by $50 \%$ ( $\mathrm{EC}_{50}$ ) values of 11 isolates of $P$ seudoperonospora humuli to fosetyl-Al and two products containing phosphorous acid. The $95 \%$ confidence intervals for the slope of regression line are $\mathbf{A}, 1.23$ to $5.43, \mathbf{B}, 0.29$ to 3.48 , and $\mathbf{C}, 0.25$ to 0.82 . 
Downy mildew did not develop in the plots in 2018 because of unfavorable weather for the disease. Phytotoxicity was not observed with any treatments, including FUNGI-PHITE and fosetyl-Al applied at $2 \times$ rates.

In 2019, all treatments reduced the severity of downy mildew compared with nontreated plots (Table 2). Percentage of disease control was statistically similar with the $1 \times$ rate of fosetyl-Al, FUNGIPHITE, and Nutri-Phite Magnum, resulting in disease control ranging from 31.6 to $77.2 \%$. Percentage of disease control was improved to 74.7 to $90.5 \%$ when the rates of fosetyl-al and FUNGI-PHITE were doubled. Even with $2 \times$ rates of these fungicides, however, disease control was still superior with either oxathiapiprolin + mandipropamid or fluopicolide (disease control of 93.7 to $96.2 \%$ ) (Table 2). Phytotoxicity was not observed with any treatment.

\section{Discussion}

Insensitivity to high levels of phosphonate fungicides occurs in $P$. humuli and seems to be prevalent in western Oregon. This finding is evidenced by fungicide control failures with multiple phosphonate products in the field, coincident with fivefold differences in the sensitivity of exposed populations and (largely) unexposed populations. Reduced sensitivity to phosphonate fungicides is not limited to individual farms but rather, is detectable across multiple farms in western Oregon.

Phosphonate resistance is relatively uncommon in plant pathogens, although several cases of reduced sensitivity and control failures are documented in oomycetes (Adaskaveg et al. 2017; Brown et al. 2004; Vegh et al. 1985). Efficacy of phosphonate is dose dependent in multiple pathosystems (Adaskaveg et al. 2015; Brown et al. 2004; Hunger and Horner 1982). Sensitivity to phosphonate may vary over an order of magnitude between isolates where resistance occurs (Adaskaveg et al. 2017) or more modestly where control failures are not reported (Dufour and Corio-Costet 2013; Feng 2018). In the few instances where insensitivity has developed, this seems to be a quantitative rather than a qualitative trait. In the case of hop downy mildew, phosphonate use and insensitivity in $P$. humuli are well documented. Hunger and Horner (1982) documented that hop downy mildew could be managed successfully with fosetyl-Al, but the authors did not demonstrate a dose-dependent efficacy of $>0.44 \mathrm{~g}$ of

Table 2. Area under the disease progress curve for hop shoots with downy mildew (caused by Pseudoperonospora humuli) in relationship to fungicide treatment where insensitivity to phosphonate fungicides was present ${ }^{y}$

\begin{tabular}{lcc}
\hline & \multicolumn{2}{c}{$\begin{array}{c}\text { Area under the disease } \\
\text { progress curve }\end{array}$} \\
\cline { 2 - 3 } Treatment & $\mathbf{2 0 1 7}$ & $\mathbf{2 0 1 9}$ \\
\hline Nontreated & $457.1 \mathrm{a}$ & $340.2 \mathrm{a}$ \\
FUNGI-PHITE: $1 \times$ rate & $501.2 \mathrm{a}$ & $115.6 \mathrm{bc}$ \\
FUNGI-PHITE: $2 \times$ rate & - & $32.4 \mathrm{~d}$ \\
Nutri-Phite Magnum fertilizer & - & $77.6 \mathrm{bc}$ \\
Fosetyl-Al: $1 \times$ rate & $478.6 \mathrm{a}$ & $232.8 \mathrm{~b}$ \\
Fosetyl-Al: $2 \times$ rate & - & $86.1 \mathrm{~cd}$ \\
Oxathiapiprolin + mandipropamid & $39.7 \mathrm{c}$ & $21.6 \mathrm{e}$ \\
Fluopicolide & $36.3 \mathrm{c}$ & $12.8 \mathrm{e}$ \\
Treatment $P$ value & $<0.0001$ & $<0.0001$ \\
Block covariance & 0.0052 & 0.0356 \\
Block $\times$ treatment covariance & 0.0324 & 0.0236 \\
Residual variance & 0.0902 & 0.1899 \\
\hline
\end{tabular}

${ }^{\mathrm{y}}$ Experiments were conducted in two commercial hop yards where evidence of insensitivity to phosphonate fungicides was confirmed by laboratory assays (Fig. 1) and the distribution of sensitivity differed significantly from that of experimental plots that received only one application of a phosphonate fungicide in the previous 13 years (Kolmogorov-Smirnov test $P<$ 0.0001).

z Each fungicide was applied three (2017) or five (2019) times at 14-day intervals beginning in early spring. Levels of downy mildew were assessed by counting the number of shoots with signs and symptoms of systemic downy mildew on each plant on each of four to five dates. Dash symbols indicate that a treatment was not evaluated in this year. Means followed by the same letter are not significantly different based on general linear mixed model $(\alpha=0.05)$.
fosetyl-Al per plant. Two decades later, Nelson et al. (2004) reported that isolates of $P$. humuli with reduced sensitivity to fosetyl-Al were prevalent in western Oregon and could be managed by doubling the dose of the fungicide. This strategy provided adequate suppression of the disease for approximately another decade. By 2016, however, phosphonate fungicides provided little or no suppression of downy mildew even when applied at the maximum rate allowable (Gent $2017 \mathrm{a}, \mathrm{b}$ ). As demonstrated herein, the pathogen population has been selected for even greater levels of insensitivity and may require fosetyl-Al rates four times greater than those used nearly 40 years earlier to obtain satisfactory suppression of downy mildew.

It is not known if there is a physiological limit to phosphonate insensitivity in $P$. humuli and other organisms. Although elevated rates of phosphonate fungicides may enable use of these products in the near term, selection for yet higher levels of insensitivity in the pathogen seems likely. There is also a limit to the dose of phosphonate that can be applied to hop and other crops without causing phytotoxicity. Plant injury from phosphonate is reported in multiple plant species (McDonald et al. 2001; Seymour et al. 1994; Walker 1989; Wicks and Hall 1990). Sensitivity to phosphonate varies with plant species, but generally, it is correlated with the dose applied and in planta concentrations of phosphonate (Barrett et al. 2004). The manufacturer's label for Aliette 80WDG also warns that phytotoxicity may occur when tank mixing with certain pesticides, adjuvants, and fertilizers. Although we did not observe phytotoxicity in the field experiments in 2018 and 2019, we did observe leaf necrosis on some plants treated with the $6 \times$ rate of FUNGI-PHITE under greenhouse conditions. In our experience, repeated use of high rates of phosphonate in the field can result in chlorosis of young hop leaves and stunted plant growth in certain cultivars. Therefore, we urge caution when considering the application of elevated rates of phosphonate to manage insensitive populations of $P$. humuli.

The temporal dynamics and persistence of phosphonate insensitivity have not been studied in detail, and it is unknown if the $P$. humuli population will revert to the sensitive phenotype if phosphonate products are not applied (Allen et al. 2017; Hawkins and Fraaije 2018). Persistence of resistant isolates in a population depends on multiple processes and factors, such as loss of resistance genes or mutation to wild-type genotype, fitness costs to the pathogen, and regrowth or reinvasion by sensitive individuals (Allen et al. 2017). One factor that is relevant for $P$. humuli is that the pathogen can establish perennial infections of the root system, resulting in chronic infection of individual plants and hop yards that enables polyetic epidemics (Coley-Smith 1965; Johnson and Anliker 1985; Royle and Kremheller 1981). This aspect of the disease biology may enable greater persistence of insensitive isolates within a hop yard compared with annual crops because of limited regrowth or reinvasion of sensitive isolates (Allen et al. 2017). In the case of phenylamide fungicides, the frequency of insensitive isolates may decline over time such that these fungicides can be reintroduced on a limited basis as observed with Phytophthora infestans on potato (Dowley et al. 2002). In contrast, phenylamide insensitivity seems to persist at high levels in $P$. humuli, even in hop yards that have not been treated in over a decade (Gent et al. 2008).

Systemic, chronic infection of hop plants by $P$. humuli also has implications for spread of insensitive isolates in association with planting material between hop yards, farms, and production regions. $P$. humuli is easily disseminated in infected rhizomes and softwood propagated plants (Royle and Kremheller 1981). Nelson et al. (2004) suggested that insensitivity to fosetyl-Al detected in southern Idaho was associated with movement of infected planting from other production regions. Indeed, genetic evidence from 2019 suggests that founder genotypes associated with infected planting material may persist for the life of a hop yard (Gent et al. 2019). Thus, there is clear risk of spreading isolates tolerant to exceptionally high rates of phosphonate fungicide within and outside the Pacific Northwest in the United States. The close genetic relatedness of isolates of $P$. humuli in the western and eastern United States (Gent et al. 2019), detection of phenylamide insensitivity (Marks and Gevens 2017), and relatively poor efficacy of fosetyl-Al (applied at $2.24 \mathrm{~kg} / \mathrm{ha}$ of active ingredient) 
in the Upper Midwest (Higgins and Hausbeck 2017) may indicate that fungicide-insensitive isolates have already been disseminated outside of Oregon.

In the absence of phosphonate fungicides, downy mildew management will require fungicides with different modes of action. There are multiple fungicides presently registered for use on hop in the United States that should provide adequate disease management, including fluopicolide as demonstrated here and others (Gent et al. 2015b). The recommendation by Hunger and Horner (1982) that the presently effective fungicides require management to delay resistance in the hop downy mildew pathogen seems more imperative now that two of the systemic fungicides that they reported on have been lost to resistance.

\section{Acknowledgments}

This work was made possible by the excellent technical support of Nanci Adair and other laboratory members. We thank Gary Vallad and two anonymous reviewers for their reviews and insightful comments that greatly improved this paper. The use of trade, firm, or corporation names in this publication is for the information and convenience of the reader. Such use does not constitute an official endorsement or approval by the U.S. Department of Agriculture or the Agricultural Research Service of any product or service to the exclusion of others that may be suitable.

\section{Literature Cited}

Adams, F., and Conrad, J. P. 1953. Transition of phosphite to phosphate in soils. Soil Sci. 75:361-371.

Adaskaveg, J. E., Förster, H., and Hao, W. 2017. Potassium phosphite resistance and new modes of action for managing Phytophthora diseases of citrus in the United States. Pages 205-210 in: Modern Fungicides and Antifungal Compounds, Vol. VIII. H. B. Deising, B. Fraaije, A. Mehl, E. C. Oerke, H. Sierotzki, and G. Stammler, eds. Deutsche Phytomedizinische Gesellschaft, Braunschweig, Germany.

Adaskaveg, J. E., Hao, W., and Förster, H. 2015. Postharvest strategies for managing Phytophthora brown rot of citrus using potassium phosphite in combination with heat treatments. Plant Dis. 99:1477-1482.

Allen, R. C., Engelstädter, J., Bonhoeffer, S., McDonald, B. A., and Hall, A. R. 2017. Reversing resistance: Different routes and common themes across pathogens. Proc. R. Soc. B 284:20171619.

Barrett, S. R., Shearer, B. L., and Hardy, G. E. StJ. 2004. Phytotoxicity in relation to in plant concentrations of fungicide phosphite in nine Western Australia native species. Australas. Plant Pathol. 33:521-528.

Bower, L. A., and Coffey, M. D. 1985. Development of laboratory tolerance to phosphorous acid, fosetyl-Al, and metalaxyl in Phytophthora capsici. Can. J. Plant Pathol. 7:1-6.

Brown, S., Koike, S. T., Ochoa, O. E., Laemmlen, F., and Michelmore, R. W. 2004. Insensitivity to the fungicide fosetyl-aluminum in California isolates of the lettuce downy mildew pathogen, Bremia lactucae. Plant Dis. 88:502-508.

Coffey, M. D. 1987. Phytophthora root rot of avocado-an integrated approach to control in California. Plant Dis. 71:1046-1052.

Cohen, J. 1988. Statistical Power Analysis for the Behavioral Sciences, 2nd Ed. Erlbaum, Hillsdale, NJ.

Cohen, Y., and Coffey, M. D. 1986. Systemic fungicides and the control of oomycetes. Annu. Rev. Phytopathol. 24:311-338.

Cohen, Y., and Samoucha, Y. 1984. Cross-resistance to four systemic fungicides in metalaxyl-resistant strains of Phytophthora infestans and Pseudoperonospora cubensis. Plant Dis. 68:137-139.

Coley-Smith, J. R. 1965. Infection of hop rootstocks by downy mildew Pseudoperonospora humuli (Miy. et Tak.) Wilson and its control by earlyseason dusts. Ann. Appl. Biol. 56:381-388.

Dolan, T. E., and Coffey, M. D. 1988. Correlative in vitro and in vivo behavior of mutant strains of Phytophthora palmivora expressing different resistances to phosphorous acid and fosetyl-Na. Phytopathology 78:974-978.

Dowley, L. J., Griffin, D., and O'Sullivan, E. 2002. Two decades of monitoring Irish populations of Phytophthora infestans for phenylamide resistance. Potato Res. 45:79-84.

Dufour, M.-C., and Corio-Costet, M.-F. 2013. Variability in the sensitivity of biotrophic grapevine pathogens (Erysiphe necator and Plasmopara viticola) to acibenzolar-S methyl and two phosphonates. Eur. J. Plant Pathol. 136:247-259.

Dunstan, R. H., Smillie, R. H., and Grant, B. R. 1990. The effects of sub-toxic levels of phosphonate on the metabolism and potential virulence factors of Phytophthora palmivora. Physiol. Mol. Plant Pathol. 36:205-220.

Feng, X. 2018. Characterization of fungicide resistance in grape powdery mildew and downy mildew using field trials, bioassays, genomic, and transcriptomic approaches: Quinoxyfen, phosphite, and mandipropamid. PhD dissertation. Virginia Polytechnic Institute and State University, Blacksburg, VA.

Fenn, M. E., and Coffey, M. D. 1989. Quantification of phosphonate and ethyl phosphonate in tobacco and tomato tissues and significance for the mode of action of two phosphonate fungicides. Phytopathology 79:76-82.
Förster, H., Adaskaveg, J. E., Kim, D. H., and Stanghellini, M. E. 1998. Effect of phosphite on tomato and pepper plants and on susceptibility of pepper to Phytophthora root and crown rot in hydroponic culture. Plant Dis. 82: $1165-1170$

Gent, D. H. 2017a. Evaluation of fungicides for hop downy mildew, Hubbard, Oregon, 2016. Plant Dis. Manage. Rept. 11:V048.

Gent, D. H. 2017b. Evaluation of fungicides for hop downy mildew, Woodburn, Oregon, 2016. Plant Dis. Manage. Rept. 11:V047.

Gent, D. H., Adair, N., Knaus, B. J., and Grunwald, N. J. 2019. Genotyping-bysequencing reveals fine-scale population differentiation in populations of Pseudoperonospora humuli. Phytopathology 109:1801-1810.

Gent, D. H., Esker, P. D., and Kriss, A. B. 2018. Statistical power in plant pathology research. Phytopathology 108:15-22.

Gent, D. H., Johnson, D. A., Gevens, A. J., and Hausbeck, M. K. 2015a. Downy mildew. Pages 15-21 in: Field Guide for Integrated Pest Management in Hops, 3rd ed. S. D. O'Neal, D. B. Walsh, and D. H. Gent, eds. U.S. Hop Industry Plant Protection Committee, Pullman, WA.

Gent, D. H., Nelson, M. E., and Grove, G. G. 2008. Persistence of phenylamide insensitivity in Pseudoperonospora humuli. Plant Dis. 92:463-468.

Gent, D. H., Twomey, M. C., Wolfenbarger, S. N., and Woods, J. L. 2015b. Preand postinfection activity of fungicides in control of hop downy mildew. Plan Dis. 99:858-865.

Gent, D. H., Ocamb, C. M., and Farnsworth, J. L. 2010. Forecasting and management of hop downy mildew. Plant Dis. 94:425-431.

Guest, D., and Bompeix, G. 1990. The complex mode of action of phosphonates. Australas. Plant Pathol. 19:113-114.

Guest, D., and Grant, B. R. 1991. The complex mode of action of phosphonates as antifungal agents. Biol. Rev. 66:159-187.

Haunold, A., Likens, S. T., Nickerson, G. B., and Hampton, R. O. 1984 Registration of Nugget hop. Crop Sci. 24:618.

Hawkins, N. J., and Fraaije, B. A. 2018. Fitness penalties in the evolution of fungicide resistance. Annu. Rev. Phytopathol. 56:339-360.

Higgins, D. S., and Hausbeck, M. K. 2017. Fungicides and cultivars can limit hop downy mildew (Pseudoperonospora humuli) in Michigan. Phytopathology S5:78

Hunger, R. M., and Horner, C. E. 1982. Control of hop downy mildew with systemic fungicides. Plant Dis. 66:1157-1159.

Johnson, D. A., and Anliker, W. L. 1985. Effect of downy mildew epidemics on the seasonal carryover of initial inoculum in hop yards. Plant Dis. 69:140-142.

Johnson, D. A., Inglis, D. A., and Miller, J. S. 2004. Control of potato tuber rots caused by oomycetes with foliar applications of phosphorous acid. Plant Dis. 88:1153-1159.

Johnson, D. A., Skotland, C. B., and Alldredge, J. R. 1983. Weather factors affecting downy mildew epidemics of hops in the Yakima Valley of Washington. Phytopathology 73:490-493.

Klein, R. E. 1994. Occurrence and incidence of metalaxyl resistance in Pseudoperonospora humuli in the Pacific Northwest. Plant Dis. 78:161-163.

Long, P. G., Miller, S. A., and Davis, L. K. 1989. Duration of fungicidal effect following injection of apple trees with fosetyl-Al. J. Phytopathol. 124:89-96.

Madden, L. V., Hughes, G., and van den Bosch, F. 2007. The Study of Plant Disease Epidemics. APS Press, St. Paul, MN.

Malusà, E., and Tosi, L., 2005. Phosphorous acid residues in apples after foliar fertilization: Results of field trials. Food Addit. Contam. 22:541e548.

Marks, M. E., and Gevens, A. J. 2017. Detection of mefenoxam-insensitive populations of Pseudoperonospora humuli in Wisconsin hop yards Phytopathology S5:62.

McDonald, A. E., Grant, B., and Plaxton, W. C. 2001. Phosphite (phosphorous acid): Its relevance in the environment and agriculture and influence on plant phosphate starvation response. J. Plant Nutr. 24:1505-1519.

McGuire, R. G. 1988. Evaluation of bactericidal chemicals for control of Xanthomonas on citrus. Plant Dis. 72:1016-1020.

McLeod, A., Masikane, S. L., Novela, P., Ma, J., Mohale, M., Nyoni, M., Stander, M., Wessels, J. P. B., and Pieterse, P. 2018. Quantification of root phosphite concentrations for evaluating the potential of foliar phosphonate sprays for the management of avocado root rot. Crop Prot. 103:87-97.

Mitchell, M. N., Ocamb, C. M., Grünwald, N. J., Mancino, L. E., and Gent, D. H. 2011. Genetic and pathogenic relatedness of Pseudoperonospora cubensis and P. humuli. Phytopathology 101:805-818

Montesinos, E., and Vilardell, P. 2001. Effect of bactericides, phosphonates and nutrient amendments on blast of dormant flower buds of pear: A field evaluation for disease control. Eur. J. Plant Pathol. 107:787-794.

Nelson, M. E., Eastwell, K. C., Grove, G. G., Barbour, J. D., Ocamb, C. M., and Alldredge, J. R. 2004. Sensitivity of Pseudoperonospora humuli (the causal agent of hop downy mildew) from Washington, Idaho, and Oregon to fosetylAl (Aliette). Plant Health Prog. 5. doi.org/10.1094/PHP-2004-0811-01-RS

Niere, J. O., DeAngelis, G., and Grant, B. R. 1994. The effect of phosphonate on the acid-soluble phosphorus components in the genus Phytophthora. Microbiology 140:1661-1670.

Noel, Z. A., Wang, J., and Chilvers, M. I. 2018. Significant influence of $\mathrm{EC}_{50}$ estimation by model choice and $\mathrm{EC}_{50}$ type. Plant Dis. 102:708-714.

Ouimette, D. G., and Coffey, M. D. 1989a. Comparative antifungal activity of four phosphonate compounds against isolates of nine Phytophthora species. Phytopathology 79:761-767. 
Ouimette, D. G., and Coffey, M. D. 1989b. Phosphonate levels in avocado (Persea americana) seedlings and soil following treatment with fosetyl-Al or potassium phosphonate. Plant Dis. 73:212-215.

Ouimette, D. G., and Coffey, M. D. 1990. Symplastic entry and phloem translocation of phosphonate. Pestic. Biochem. Physiol. 38:18-25.

Royle, D. J., and Kremheller, H. T. H. 1981. Downy mildew of the hop. Pages 395-419 in: The Downy Mildews. D. M. Spencer, ed. Academic Press, New York, NY.

Sanders, P. L., Coffey, M. D., Greer, G. D., and Soika, M. D. 1990. Laboratoryinduced resistance to fosetyl-Al in a metalaxyl-resistant field isolate of Pythium aphanidermatum. Plant Dis. 74:690-692.

Sebaugh, J. L. 2011. Guidelines for accurate EC50/LC50 estimation. Pharm. Stat. 10:128-134.

Seymour, N. P., Thompson, J. P., and Fiske, M. L. 1994. Phytotoxicity of fosetyl$\mathrm{Al}$ and phosphonic acid to maize during production of vescicular arbuscular mycorrhizal inoculum. Plant Dis. 78:441-446.

Skotland, C. B., and Johnson, D. A. 1983. Control of downy mildew of hops. Plant Dis. 67:1183-1185.
Smillie, R., Grant, B. R., and Guest, D. 1989. The mode of action of phosphite: Evidence for both direct and indirect modes of action on three Phytophthora spp. in plants. Phytopathology 79:921-926.

Stehmann, C., and Grant, B. R. 2000. Inhibition of the glycolytic pathway and hexose monophosphate bypass by phosphonate. Pestic. Biochem. Physiol. 67:13-24.

Vegh, I., Leroux, P., Le Berre, A., and Lanen, C. 1985. Detection on Chamaecypari lawsoniana 'Ellwoodii' of a strain of Phytophthora cinnamomi resistant to fosetyl-Al. Rev. Hortic. 262:19-21.

Walker, G. E. 1989. Phytotoxicity in mandarins caused by phosphorous acid Australas. Plant Pathol. 18:57-59.

Wicks, T., and Hall, T. 1990. Evaluation of phosphonic (phosphorous) acid for the control of Phytophthoora cambivora on almond and cherry in South Australia. Australas. Plant Pathol. 19:132-133.

Woods, J. L., Dreves, A. J., James, D. G., Lee, J. C., Walsh, D. B., and Gent, D. H. 2014. Development of biological control of Tetranychus urticae (Acar: Tetranychidae) and Phordon humuli (Hemiptera: Aphididae) in Oregon hop yards. J. Econ. Entomol. 107:570-581. 